\title{
Rating impacts in a multi-stressor world: a quantitative assessment of 50 stressors affecting the Great Lakes
}

\author{
Sigrid D. P. Smith,${ }^{1,16}$ Peter B. Mcintyre, ${ }^{2}$ Benjamin S. Halpern, $, 3,4$ Roger M. Cooke, ${ }^{6}$ Adrienne L. \\ Marino, ${ }^{1,17}$ Gregory L. Boyer, ${ }^{7}$ Andy Buchsbaum, ${ }^{8}$ G. A. Burton, Jr., ${ }^{1}$ Linda M. Campbell, ${ }^{9}, 18$ Jan J. H. \\ Ciborowski, ${ }^{10}$ Patrick J. Doran, ${ }^{11}$ Dana M. Infante, ${ }^{12}$ Lucinda B. Johnson, ${ }^{13}$ Jennifer G. Read,${ }^{1,17}$ \\ Joan B. Rose, ${ }^{12}$ Edward S. Rutherford, ${ }^{14}$ Alan D. Steinman, ${ }^{15}$ and J. David Allan ${ }^{1}$ \\ ${ }^{1}$ School of Natural Resources and Environment, University of Michigan, Ann Arbor, Michigan 48109 USA \\ ${ }^{2}$ Center for Limnology, University of Wisconsin, Madison, Wisconsin 53706 USA \\ ${ }^{3}$ Bren School of Environmental Science and Management, University of California, Santa Barbara, California 93106 USA \\ ${ }^{4}$ Imperial College London, Silwood Park Campus, Buckhurst Road, Ascot SL5 7PY United Kingdom \\ ${ }^{5}$ National Center for Ecological Analysis and Synthesis, 735 State Street, Suite 300, Santa Barbara, California 93101 USA \\ ${ }^{6}$ Resources for the Future, Washington, D.C. 20036 USA \\ ${ }^{7}$ Great Lakes Research Consortium and College of Environmental Science and Forestry, State University of New York, Syracuse, \\ New York 13210 USA \\ ${ }^{8}$ Great Lakes Regional Center, National Wildlife Federation, Ann Arbor, Michigan 48104 USA \\ ${ }^{9}$ School of Environmental Studies and Department of Biology, Queen's University, Kingston, Ontario K7L $3 N 6$ Canada \\ ${ }^{10}$ Department of Biological Sciences, University of Windsor, Windsor, Ontario N9B3P4 Canada \\ ${ }^{11}$ The Nature Conservancy Great Lakes Project, Lansing, Michigan 48906 USA \\ ${ }^{12}$ Department of Fisheries and Wildlife, Michigan State University, East Lansing, Michigan 48824 USA \\ ${ }^{13}$ Natural Resources Research Institute, University of Minnesota, Duluth, Minnesota 55881 USA \\ ${ }^{14}$ NOAA, Great Lakes Environmental Research Lab, Ann Arbor, Michigan 48015 USA \\ ${ }^{15}$ Annis Water Resources Institute, Grand Valley State University, Muskegon, Michigan 49441 USA
}

Abstract. Ecosystems often experience multiple environmental stressors simultaneously that can differ widely in their pathways and strengths of impact. Differences in the relative impact of environmental stressors can guide restoration and management prioritization, but few studies have empirically assessed a comprehensive suite of stressors acting on a given ecosystem. To fill this gap in the Laurentian Great Lakes, where considerable restoration investments are currently underway, we used expert elicitation via a detailed online survey to develop ratings of the relative impacts of 50 potential stressors. Highlighting the multiplicity of stressors in this system, experts assessed all 50 stressors as having some impact on ecosystem condition, but ratings differed greatly among stressors. Individual stressors related to invasive and nuisance species (e.g., dreissenid mussels and ballast invasion risk) and climate change were assessed as having the greatest potential impacts. These results mark a shift away from the longstanding emphasis on nonpoint phosphorus and persistent bioaccumulative toxic substances in the Great Lakes. Differences in impact ratings among lakes and ecosystem zones were weak, and experts exhibited surprisingly high levels of agreement on the relative impacts of most stressors. Our results provide a basin-wide, quantitative summary of expert opinion on the present-day influence of all major Great Lakes stressors. The resulting ratings can facilitate prioritizing stressors to achieve management objectives in a given location, as well as providing a baseline for future stressor impact assessments in the Great Lakes and elsewhere.

Key words: aquatic; cumulative impact mapping; ecological risk assessment; environmental threats; expert elicitation; expert judgment; questionnaire; weight of evidence.

Manuscript received 20 February 2014; revised 8 August 2014; accepted 29 August 2014. Corresponding Editor: J. D. Olden.

${ }^{16}$ E-mail: sdpsmith@umich.edu

${ }^{17}$ Present address: University of Michigan Water Center, Graham Sustainability Institute, University of Michigan, Ann Arbor, Michigan 48109 USA.

18 Present address: Environmental Science Program, St. Mary's University, Halifax, Nova Scotia B3H 3C3 Canada.

\section{INTRODUCTION}

Ecosystems can be affected by dozens of environmental stressors that act together to impair ecosystem condition and biodiversity status. For example, of 25 distinct stressors mapped in nearshore areas of the California Current in the Pacific Ocean, individual locations are affected by an average of 13 stressors and as many as 23 stressors (Halpern et al. 2009). Similarly, of 34 distinct stressors mapped in nearshore areas of the Laurentian Great Lakes, individual locations experience an average of 12 stressors and as 
TABLE 1. Summary of environmental stressor groups prioritized in previous assessments of the Laurentian Great Lakes.

\begin{tabular}{|c|c|c|c|c|c|}
\hline Environmental stressor group & GLRI & GLRC & SOLEC & IJC & BCS \\
\hline Toxic point source pollutants and contaminated sediments & $\mathrm{X}$ & $\mathrm{X}$ & $\mathrm{X}$ & $\mathrm{X}$ & $\mathrm{E}, \mathrm{M}$ \\
\hline Invasive species & $\mathrm{X}$ & $\mathrm{X}$ & $\mathrm{X}$ & $\mathrm{X}$ & $\mathrm{X}$ \\
\hline Nonpoint pollutants (including agricultural, forestry, and urban sources) & $\mathrm{X}$ & $\mathrm{X}$ & $\mathrm{X}$ & $\mathrm{X}$ & $\mathrm{X}$ \\
\hline Altered water level fluxes (often as climate change impact) & & & $\mathrm{X}$ & & \\
\hline Climate change & & & $\mathrm{X}$ & $\mathrm{X}$ & $\mathrm{X}$ \\
\hline Shoreline hardening and alterations, aquatic habitat alterations & $\mathrm{X} \dagger$ & $\mathrm{X}_{\dagger}^{\dagger}$ & $\mathrm{X}$ & & $\mathrm{H}, \mathrm{E}, \mathrm{M}$ \\
\hline Coastal/urban development & $\mathrm{X} \dagger$ & $\mathrm{X}_{\dagger}^{\dagger}$ & $\mathrm{X}$ & $\mathrm{X}$ & $\mathrm{X}$ \\
\hline Natural resource use (including water withdrawals) & & & $\mathrm{X}$ & & \\
\hline Nuisance algae (harmful algal blooms, Cladophora) & & & $\mathrm{X}$ & $\mathrm{X}$ & \\
\hline Dams and barriers & & & & & $\mathrm{X}$ \\
\hline
\end{tabular}

Notes: Several basin-wide plans are shown: Great Lakes Restoration Initiative (GLRI; White House Council on Environmental Quality et al. 2010), Great Lakes Regional Collaboration (GLRC; GLRC 2005), State of the Great Lakes from the State of the Lakes Ecosystem Conference (SOLEC; Environment Canada and USEPA 2009), Biennial Report from the International Joint Commission (IJC; IJC 2011), and Biodiversity Conservation Strategies (BCS; Pearsall et al. 2013). "X" denotes a focus on the listed group of stressors. "H," "M," and "E" refer to the individual plans for Lake Huron (Franks Taylor et al. 2010), Lake Michigan (Pearsall et al. 2012b), and Lake Erie (Pearsall et al. 2012a), respectively; these entries highlighted a stressor not highlighted in Pearsall et al. (2013).

$\dagger$ Indicates a plan in which habitat alterations were highlighted more generally, sometimes including land conversion to other uses besides development.

many as 31 stressors (Allan et al. 2013). In the Great Lakes, these stressors differ greatly in their spatial scale and pathways of impact, which can drive nonlinear species responses (Bails et al. 2005, Allan et al. 2013). In this and other ecosystems, the lack of relevant scientific data, disagreements among stakeholders about objectives, and an inability to target individual drivers and species within complex socioecological systems are daunting challenges (e.g., Rodríguez Iglesias and Kothmann 1998, Steinman et al. 2002, Metcalf et al. 2010, Burgman et al. 2011, Martin et al. 2012). Indeed, ongoing efforts to restore the Great Lakes, including a recent investment of more than USD \$1 billion through the Great Lakes Restoration Initiative (White House Council on Environmental Quality 2010), exemplify the challenges of developing effective large-scale restoration plans in a multi-stressor context.

An understanding of all relevant stressors is critical to prioritizing conservation actions, including restoration, protection, and management (Salafsky et al. 2008). Yet, we rarely have sufficient empirical evidence, such as comprehensive factorial experiments or detailed field studies, on the separate and cumulative impacts of all major stressors to inform decisions (e.g., Halpern et al. 2007, Crain et al. 2008, Martin et al. 2012). Consequently, managers often rely on the judgment of experts to prioritize places, problems, and types of impacts while developing management and restoration plans (e.g., Martin et al. 2012). In the Great Lakes, a number of these expert-based stressor rankings are available (Table 1), but most are qualitative and coarse in their handling of individual, actionable stressors. While these rankings represent the best available management guidance, group dynamics and peer influence may undermine their repeatability and lead to misinterpretations (see Bikhchandani et al. 1992, Halpern et al. 2007, Aspinall 2010, Kappel et al. 2012, Martin et al. 2012). In the Great
Lakes, most reports have been based on rating stressors qualitatively in broad categories (e.g., toxic chemicals, invasive species), lumping together diverse stressors with different spatial distributions and ecological effects (see Allan et al. 2013). As a result, restoration plans often focus on a few serious stressors in the belief that alleviating them will result in ecosystem improvement despite the continuing influence of many additional stressors (Wohl et al. 2005).

The ecological impact of a particular stressor is often believed to differ by habitat, such that habitat characterization and customization have been considered essential in large-scale conservation planning efforts for aquatic ecosystems (e.g., National Fish Habitat Action Plan [McKenna and Castiglione 2010]). In one of few aquatic studies examining impacts for a comprehensive suite of stressors, experts judged the average impact of stressors to be higher in coastal than offshore habitats in the California Current, with six stressors having particularly strong differences (Teck et al. 2010). Differences in stressor impacts among habitats are likely in the Great Lakes as well, since the physiological tolerances and species interactions of aquatic plants and animals can change based on the abiotic context, leading to community-wide differences in responses to stressors among habitats (Keough et al. 1999, Trebitz et al. 2009, McKenna and Castiglione 2010, Riseng et al. 2011, Larson et al. 2013). Beyond ecosystem structure and function, the types and levels of human disturbance differ by habitat in the Great Lakes (Allan et al. 2013, Larson et al. 2013). Thus, it is not surprising that biotic responses to suites of stressors can differ among ecosystem zones (e.g., Hecky et al. 2004) and lakes (Brazner et al. 2007).

In this study, we used expert elicitation to develop quantitative, habitat-specific ratings of the potential relative impacts of 50 stressors on the Laurentian Great 
Lakes ecosystem. A subset of these impact ratings were used by Allan et al. (2013) as stressor weightings for a spatial analysis of cumulative stress in the Great Lakes. However, the results of the elicitation offer many more insights into expert opinion on stressor impacts than is evident from the average impact ratings alone. In this paper, we present the process and results of our survey in detail. We address three key conceptual questions: (1) Which stressors have the greatest and least potential impact? (2) Does stressor potential impact differ by habitat? (3) Is there agreement among professionals regarding the relative importance of individual stressors or broad categories of stressors? We hypothesized that categories of stressors highlighted in previous Great Lakes assessments, such as toxic chemicals, invasive species, and nonpoint source pollutants (Table 1), would be rated most highly, but that individual stressors within each broad category might differ widely. We also expected substantial differences in the rating of the same stressor among specific lakes and ecosystem zones, reflecting fundamental physical differences that mediate potential impacts on species and ecosystems. Finally, we expected general agreement among scientific and management experts regarding the relative importance of each stressor, because decades of basin-wide initiatives and professional conferences have allowed consensusbuilding around major threats.

\section{Methods}

\section{Survey instrument design and distribution}

We designed a detailed online survey to evaluate the relative potential ecosystem impact of 50 stressors in the Laurentian Great Lakes (see Fig. 1 for stressor list and Appendix A for details and the survey instrument). This work was completed under the Great Lakes Environmental Assessment and Mapping project, which focuses on geospatial analysis of environmental stressors and ecosystem services (see Allan et al. 2013). We considered a stressor to be a substance, condition, human activity, or taxon likely to alter the aquatic ecosystem and subsequently impair habitats, biota, or ecosystem processes. Specifically, our list of 50 stressors within eight broad categories was developed by considering factors that had (1) potential to alter the biology, chemistry, or physical structure of the lakes themselves; (2) distinct pathways or mechanisms of impact from all other included stressors (i.e., focusing on the actual driver of change rather than the activity when possible; distinction discussed in Halpern and Fujita [2013]), and (3) potential to access or develop spatially explicit data on stressor intensity across all five of the Great Lakes. We asked respondents to focus on present-day effects of each stressor (manifested within the last five years), ignoring historic stressors unless they had continuing importance. We also instructed respondents to focus on how each stressor influences ecosystem condition or functioning, rather than human health. Respondents were allowed to skip questions as desired.
Several elicitation techniques have been used for risk assessment and prioritization of environmental stressors, and each has both advantages and drawbacks (Appendix A). We used an individually administered survey that followed an indirect elicitation approach, in which experts answer a series of focused questions and data analysts further process the responses to derive the information needed (Weber and Borcherding 1993, Low Choy et al. 2009, Martin et al. 2012). More specifically, we quantified potential ecosystem impacts of stressors by conceptualizing impacts along five axes or components (spatial extent, temporal frequency, ecological scope, magnitude of change, and recovery time) using a risk assessment framework previously applied in marine stressor analyses (Halpern et al. 2007, Teck et al. 2010, Kappel et al. 2012; Table 2). Based on this methodology, each component was weighted using multi-attribute utility theory, and stressor ratings for each component were summed to yield the total potential ecosystem impact for that stressor. Rather than asking experts to implicitly conceptualize and merge many types of impacts into an overall weighting, this framework spurs experts to explicitly consider different pathways of impact separately, yielding a more objective judgment (Teck et al. 2010). In addition to transparency and repeatability, a key benefit of this style of elicitation is that the results can be updated with new stressors without repeating the entire survey; in this case, one only needs to assess the five component ratings for a new stressor to rate its impact relative to stressors studied previously (Kappel et al. 2012).

Our survey had four sections. Part I assessed respondents' demographics, professional activities, and training, allowing us to examine the composition of our respondents and test for response bias (White et al. 2005). In Part II, we assessed stressor importance via direct elicitation (eliciting an overall judgment without breaking down the judgment into subcomponents). We asked respondents to rank stressors by qualitatively choosing the five most significant individual stressors from the full list of 50 stressors. We gauged understanding of the survey and completeness of our stressor list by asking respondents to identify any stressors affecting their focal ecosystem that they felt were missing. Responses indicated that relatively few stressors were not represented in the survey. (Appendix B: Table B1). Also, we asked respondents to partition the total impact of human activities among the eight categories of stressors. These questions allowed us to compare the relative importance of stressors derived from a direct elicitation approach to the indirect approach used in the rest of the survey.

In Part III, we assessed which components of ecosystem impact (Table 2) are most important in the Great Lakes. This was the first of two sets of data needed to rate stressors via indirect elicitation; we collected this information to tease apart and weight the different kinds of impact a stressor exerts on 


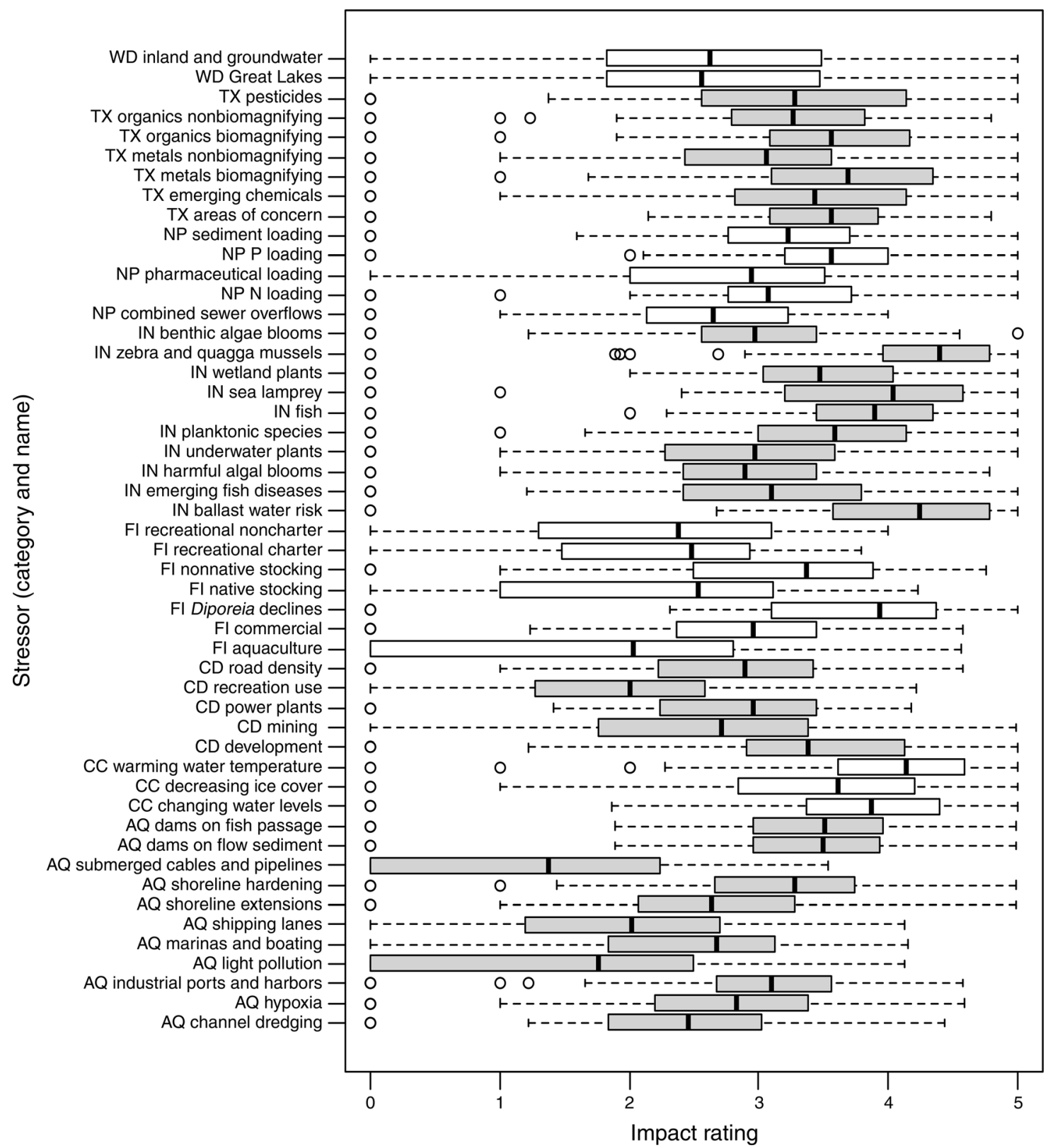

FIG. 1. Boxplots of ecosystem impact ratings for each of 50 environmental stressors in the Laurentian Great Lakes based on expert elicitation. Colors of boxplot bodies alternate between gray and white to distinguish categories visually. Ratings on a 0 (no impact)-5 (highest impact) scale were derived from the indirect elicitation framework (Parts III and IV of survey) and calculated by individual respondent to show variation among respondents; data were pooled across habitats. Boxplots show medians and quartiles as boxes, $1.5 \times$ interquartile range as whiskers, and outliers as circles. Stressor categories include (top to bottom) water withdrawals and diversions (WD), toxic chemicals (TX), nonpoint source pollutants (NP), invasive and nuisance species (IN), fisheries (FI), coastal development (CD), climate change (CC), and aquatic habitat alterations (AQ).

ecosystems. After defining the five components of ecosystem impact, we presented 20 scenarios representing hypothetical stressors, showing impacts on a fivepoint scale of intensity. We asked respondents to rank the five scenarios having the most significant overall impacts on ecosystem health. We delimited the numerical rating scales using a $\log _{10}$ scale for all components of impact except the magnitude of change (Appendix A).
In Part IV of the survey, respondents assessed the potential impact of each stressor based on the five components of ecosystem impact from Part III. This was the second set of data needed to indirectly rate stressors; these ratings, along with their weights from Part III, allowed us to use weighted sums to calculate the relative impact of each stressor (referred to as habitat vulnerability in Halpern et al. [2007]). We asked respondents to 
TABLE 2. Components of ecosystem impacts used for rating environmental stressors, including the designated rating scale ranges and descriptions.

\begin{tabular}{|c|c|c|}
\hline Component of impact & Rating scale range & Brief description \\
\hline Spatial extent & 0 (no impact)-5 (very broad, $>20000 \mathrm{~km}^{2}$ ) & $\begin{array}{l}\text { spatial scale at which a single stressor occurrence } \\
\text { impacts the ecosystem }\left(\mathrm{km}^{2}\right)\end{array}$ \\
\hline Temporal frequency & 0 (never) -5 (near-continuous, $>180$ days/year) & $\begin{array}{l}\text { average frequency of stressor occurrence at a } \\
\text { particular location (occurrences per year, or days } \\
\text { per year for prolonged events) }\end{array}$ \\
\hline Ecological scope & 0 (no impact) -5 (whole community) & $\begin{array}{l}\text { extent of impact of a stressor on the structure and/ } \\
\text { or function of a species, community, or food web } \\
\text { in an ecosystem }\end{array}$ \\
\hline Magnitude of change & 0 (no change) -5 (very high, $75-100 \%$ ) & $\begin{array}{l}\text { degree to which the "natural" state of an ecosystem } \\
\text { is altered by a stressor (percentage change from } \\
\text { previous conditions) }\end{array}$ \\
\hline Recovery time & 0 (immediate) -5 (very long, $>50$ years) & $\begin{array}{l}\text { likely time for the focal ecosystem to return to } \\
\text { previous conditions following the end of a } \\
\text { disturbance (months or years) }\end{array}$ \\
\hline
\end{tabular}

consider one episode of a given stressor, comparing the relative impact of that stressor if all other stressors were present at high levels. We asked respondents to rate stressors independent of their actual spatial patterns in intensity and to consider the highest levels of impact so that weightings reflected maximum potential impact. Respondents filled in blank cells in a data table or marked "no impact" if a stressor was not important in their focal habitat(s).

To investigate whether respondents would differentially weight stressor impacts by habitat, we collected responses regarding stressor impacts (Parts IIA and IV) by individual lake and ecosystem zone. Hereafter, we refer to each combination of lake and ecosystem zone as a habitat. The six ecosystem zones considered were (1) coastal wetlands and rivermouths, (2) littoral, hard substrate, (3) littoral, soft substrate, (4) sublittoral, hard substrate, (5) sublittoral, soft substrate, and (6) offshore (Allan et al. 2013). Respondents were asked to select the lakes and ecosystem zones to which their answers were applicable or to assign their answers explicitly to all lakes and/or ecosystem zones to allow us to calculate habitat-specific stressor impact ratings.

We defined experts as researchers, managers, and nongovernmental organization (NGO) representatives developing and using scientific knowledge (see Appendix A for details). Active researchers identified by literature searches and by peers formed our largest survey group ( $n$ $=455$ addressees), with additional addressees from lists provided by management entities $(n=203$ additional addressees) and nonprofit organizations $(n=129$ additional addressees). Since some individuals were identified from multiple sources or did multiple professional activities, we used respondents' self-declared primary work activity when making comparisons of stressor ratings among groups. To check the composition of these groups, we tested for differences in gender among groups using a contingency table analysis (CTA; Zar 1999) and differences in year of birth using a Kruskal-Wallis test.

\section{Survey data analysis}

All responses were screened and filtered for invalid and incomplete answers. Invalid answers (e.g., responses not providing the requested number of selections in Parts II and III) were removed prior to analysis, but partial answers were allowed in Part IV. Most data processing and analyses were performed in R 2.13 ( R Development Core Team 2011), and a significance level $(\alpha)$ of 0.05 was used for statistical tests. As a measure of potential response bias, we tested for differences in survey completion (selecting a button to record responses vs. not) based on gender (CTA; after excluding five individuals who declined to answer), position type (CTA; academic, agency, NGO, or other), and year of birth (Kruskal-Wallis test). We were unable to assess non-response bias due to a lack of background data about non-respondents.

To derive weights for each component of ecosystem impact, we analyzed the scenario comparisons (Part III) using probabilistic inversion from multi-attribute utility theory (details in Appendix A and Teck et al. [2010]). In essence, this procedure estimates how the survey respondents viewed the relative importance of the five components of impact based on how they ranked the 20 hypothetical scenarios. These weights were normalized to sum to one, such that each weight can be interpreted as the proportion of the total impact of a stressor attributable to that component; confidence intervals reflect how much agreement is shown by respondents.

To derive final ratings of the potential impact of each of the 50 stressors, we summed the scores for the five components of impact (from Part IV) after weighting each by its importance (from Part III). Thus, scores $(S)$ for each stressor $i=1-50$ in each habitat $j=1-30$ were calculated as

$$
S_{i j}=\sum_{i=1}^{5}\left(W_{k} \times R_{i j k}\right)
$$

where $W$ is the weight for components of impact $k=$ $1-5$, and $R$ is the rating of each component of impact $k$ 
customized for each stressor $i$ and each habitat $j$. For most analyses, we averaged the ratings of the individual components of impact for all respondents and then computed group-wide stressor scores using the weight matrix multiplied by the average ratings. In addition, to evaluate the consistency of ratings among individual respondents, we assessed ratings for each stressor from each respondent separately; these individual-based scores were customized for each work activity group, but not for habitats.

Summary statistics from valid responses were used to examine differences among stressors, habitats (lakes and ecosystem zones), and respondents. When multiple values were tied, we assigned their ranks as the midpoint of their range in rank. We totaled the number of "top five" selections for each stressor to produce a stressor ranking based on direct elicitation (Part IIA), and we used a Spearman rank correlation test ( $\rho$; Zar 1999) to examine concordance in ranking stressors by indirect (Part III-IV) and direct (Part IIA) elicitation. We examined differences among lakes and ecosystem zones based on the ranges of stressor ratings and based on Spearman rank correlations of ratings for each pair of habitats. Since we found that differences among habitats were small, we averaged the ratings across the 30 lakeecosystem zones to summarize differences among stressors more succinctly (see Results: Stressor importance averaged across habitats).

For the stressor category weights collected in Part IIC, we tested for differences in ratings of impact among primary work activity groups using an unequal variances one-way ANOVA (Welch adjustment; Welch 1951). We used an arcsine-square-root transformation to improve conformation to normality assumptions.

\section{Results}

Of the 787 invitations, 306 individuals opened the survey, and 141 respondents completed portions of Part IV as instructed (Appendix B: Table B2). Primary work activities of respondents (Part I) were 58\% scientific research ( $n=157$ individuals), 21\% natural resource management $(n=57)$, and $21 \%$ other activities $(n=58)$. The other primary work activities (combined for subsequent analyses) included restoration ( $n=11)$, advocacy $(n=15)$, policy $(n=12)$, and unlisted activities such as teaching $(n=20)$. Many respondents had experience or expertise with multiple categories of stressors (median $=3$ categories). All stressor categories, lakes, and ecosystem zones had a good representation of experts. The number of experts with experience or expertise was at least 50 for each category, 127 for each lake, and 108 for each ecosystem zone (Appendix B: Table B3, Fig. B2). We found no significant differences between those finishing and not finishing the survey in gender, position type, or age (Appendix A, Appendix B: Fig. B1).

Responses to the scenarios in Part III indicated similar levels of importance among all five components of ecosystem impact (Appendix B: Table B4). Recovery time was judged the most important component (weighted $\sim 23 \%$ of total impact) and temporal frequency of stressor occurrence was judged the least important component (weighted $\sim 13 \%$ ). Weightings were similar among primary work activity groups.

\section{Stressor importance averaged across habitats}

Stressors differed greatly in potential impact. The average stressor scores from indirect elicitation (Parts III-IV) ranged widely on the $0-5$ scale, from 1.64 to 4.24. Individual stressors were distributed evenly between these two extremes (Fig. 1). The highest-rated stressors were related to invasive and nuisance species and climate change (Table 3 ). Invasive zebra and quagga mussels (Dreissena polymorpha and Dreissena rostriformis bugensis, respectively) were rated as the highestimpact stressor (Table 3). Ballast water invasion risk and climate change effects related to warming temperature were also rated highly (Table 3). Lowest-rated stressors were submerged cables and pipelines, light pollution, and coastal recreational use. Respondents on average selected 1.9 stressors as having "no impact," and only five stressors had a notable fraction $(\sim 14 \%$ for each) of the 141 respondents selecting "no impact."

Broad differences in the estimated ecological impact among stressor categories were apparent. For example, invasive and nuisance species as a whole were assessed to have higher impact than water withdrawals and diversions, both in terms of individual stressors (Fig. 1) and in direct elicitation of ratings of the eight higherlevel categories (Fig. 2). However, these category comparisons did not capture all differences among individual stressors, since several higher-level categories had a mix of individual stressors of low and high importance (e.g., averages of stressor impacts for individual stressors within the fisheries category ranged 1.82-3.37; Fig. 1).

Many stressors were ranked similarly in the indirect (Parts III-IV) vs. direct (Part IIA) stressor impact rankings (Table 3; Spearman rank correlation test: $\rho=$ $0.83, P<0.001)$. However, eight stressors changed rank by more than 12 places when comparing the two elicitation formats. For example, harmful algal blooms (proliferation of nuisance algae), combined sewer overflows, and lake water withdrawals had higher importance based on the direct "top five" rankings than the indirect rankings, while coastal power plants, biomagnifying toxic metals, and non-biomagnifying toxic organics all ranked lower in the direct "top five" rankings.

\section{Habitat comparisons}

The experts responding to our survey indicated similar potential impacts of stressors across lakes and ecosystem zones (Tables 4 and 5), even among respondents answering for specific lakes and ecosystem zones rather than selecting "all" (most often answering 
TABLE 3. The 10 environmental stressors having the most potential impact in the Laurentian Great Lakes based on two types of expert elicitation.

\begin{tabular}{lcc}
\hline \hline \multicolumn{1}{c}{ Stressor } & Indirect ratings & Direct selections \\
\hline Invasive mussels & $4.24(1)$ & $92(1)$ \\
Climate, warming temperature & $4.12(2)$ & $50(6)$ \\
Invasion risk via ballast water & $4.08(3)$ & $67(2)$ \\
Invasive lamprey & $3.86(4)$ & $39(7.5)$ \\
Invasive fish & $3.81(5)$ & $56(5)$ \\
Climate, changing water levels & $3.78(6)$ & $39(7.5)$ \\
Toxic metals, biomagnifying & $3.75(7)$ & $18(22)$ \\
Fisheries, Diporeia decline & $3.75(8)$ & $23(17)$ \\
Toxic organics, biomagnifying & $3.64(9)$ & $21(19.5)$ \\
Nonpoint P loading & $3.60(10)$ & $58(4)$ \\
Coastal development & $3.47(14)$ & $60(3)$ \\
Nonpoint sediment loading & $3.24(20)$ & $34(9)$ \\
Nuisance harmful algal blooms & $2.78(34)$ & $32(10)$ \\
\hline
\end{tabular}

\begin{abstract}
Notes: In the indirect elicitation approach (indirect ratings), we calculated scores on a 0 (no impact)-5 (highest impact) scale based on a weighted sum of ratings of five components of ecosystem impact (Parts III and IV of the survey, averaged across habitats; $n=141$ respondents). For comparison, we totaled the number of people ranking stressors as one of their five most significant from our list of 50 stressors in a direct elicitation exercise (direct selections; Part IIA of the survey, pooled across habitats; $n=196$ respondents). The rank of each stressor within the list of 50 stressors is shown in parentheses for both columns, with averaging used for ties. Each rank was calculated after completing the indirect or direct score calculations.
\end{abstract}

for one of five lakes and three of six ecosystem zones). The ranges across the 30 lake-ecosystem-zone combinations for individual stressor ratings were small compared to differences among stressors (ranges for 50 stressors: mean 0.34, range 0.16-0.73; Supplement). For example, the quantitative score for invasive mussels across habitats (mean 4.24) was the highest stressor in 26 of the 30 lake-ecosystem zone combinations, ranging from 4.12 for Lake Superior wetlands and rivermouths to 4.36 for Lake Michigan offshore. Scores for every pair of habitats were highly correlated (Spearman correlations; $n=435$, $\rho$ average 0.98 , $\rho$ range $0.93-$ 1.00). However, weak trends by habitats were seen for some stressors. For example, while emergent invasive plants (e.g., common reed, Phragmites australis subsp. australis) were rated as a moderate stressor overall, they ranked as the fifth most important stressor in wetlands and rivermouths (Table 5). Similarly, while the decline of hypolimnetic amphipods in the genus Diporeia (an invertebrate prey for valued fish populations) was ranked fourth to sixth in most ecosystem zones, they ranked much lower in wetlands and rivermouths (Table 5).

\section{Respondent comparisons}

When grouped by primary work activity, the respondent groups significantly differed in the direct weights they gave to three categories of stressors. Compared to researchers and other respondents, natural resource managers weighted the climate change and nonpoint pollution categories lower and weighted invasive and nuisance species higher (one-way ANOVA, climate change: $F=5.66$, df $=2,98.6, P=0.005$, nonpoint pollution: $F=4.86$, df $=2,96.5, P=0.01$, invasive/ nuisance species: $F=6.88, \mathrm{df}=2,99.9, P=0.002$; Fig. 2). When using the indirect framework for rating stressor

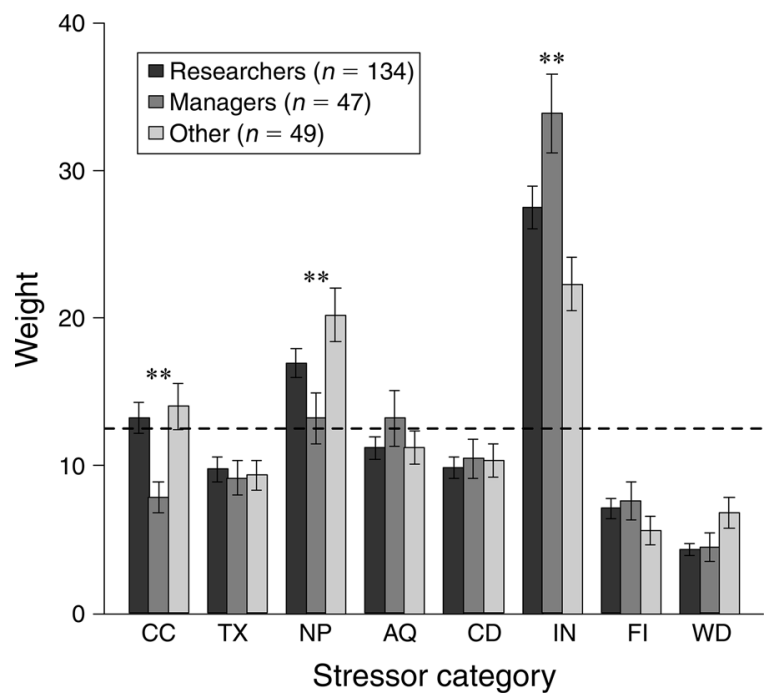

FIG. 2. Weights (percentage of total impact, mean \pm SE) representing the importance of eight categories of stressors in the Laurentian Great Lakes from a survey of experts (Part IIC of survey, $n=230$ complete responses). Data are shown by the self-declared primary work activity of respondents, which included scientific research (researchers; black bars), natural resource management (managers; gray bars), or other activities (other; light gray bars). Using a direct elicitation approach, respondents were asked to partition total impact among the eight categories. Significant differences among groups (tested for each category separately) are indicated by asterisks (** $P<$ 0.01). The black dotted line represents the null expectation of equal weights for each of the eight categories. Stressor categories include (left to right) climate change (CC), toxic chemicals (TX), nonpoint source pollutants (NP), aquatic habitat alterations (AQ), coastal development (CD), invasive and nuisance species (IN), fisheries (FI), and water withdrawals and diversions (WD). 
TABLE 4. Ranks of the five highest-rated environmental stressors by lake based on expert elicitation in the Laurentian Great Lakes; rankings are also reported when a stressor was ranked 1-5 in an individual lake.

\begin{tabular}{lccccrr}
\hline \hline \multicolumn{1}{c}{ Stressor } & $\begin{array}{c}\text { All lakes } \\
(n=72)\end{array}$ & $\begin{array}{c}\text { Lake Superior } \\
(n=67)\end{array}$ & $\begin{array}{c}\text { Lake Michigan } \\
(n=91)\end{array}$ & $\begin{array}{c}\text { Lake Huron } \\
(n=104)\end{array}$ & $\begin{array}{c}\text { Lake Erie } \\
(n=94)\end{array}$ & $\begin{array}{c}\text { Lake Ontario } \\
(n=69)\end{array}$ \\
\hline Invasive mussels & 1 & 3 & 1 & 2 & 1 & 1 \\
Climate, temperature & 2 & 6 & 12 & 8 & 3 & 3 \\
Invasive ballast risk & 3 & 1 & 2 & 1 & 2 & 2 \\
Toxic biomagnifying metals & 4 & 8 & 8 & 12 & 5 & 16 \\
Climate, water level & 5 & 4 & 3 & 5 & 5 & 11 \\
Invasive lamprey & 6 & 2 & 5 & 4 & 4 \\
Invasive fish & 7 & 5 & 4 & 5 & 26 \\
Diporeia decline & 13 & 14 & 4 & 5 & 7 \\
\hline
\end{tabular}

Notes: Ranks were derived from experts rating five components of ecosystem impact for each stressor in an indirect elicitation framework (Parts III and IV of survey). Experts selected the lake to which their answers applied, or selected "All lakes" if their responses applied to all lakes ( $n$ indicates the number of survey respondents for each lake).

impact, the pattern of weightings for the five components of ecosystem impact by researchers and managers was identical; both assigned markedly lower importance to temporal frequency of stressor occurrence. Those with other primary work activities also weighted frequency of stressor occurrence lower, but tended toward greater equality among the five components. However, individual respondents did not have wide differences in opinion on most stressor scores (CV of individual-based scores for 50 stressors: mean $41 \%$, range 19-77\%; Fig. 1). For example, in rating ballast water invasion risk, respondents in the middle $50 \%$ had a range of less than one in their scores (CV 22\%, interquartile range (IQR) 3.57-4.78; Fig. 1). Even stressors with the highest variance did not have particularly wide ratings; for example, the 75th percentile of light pollution was below the IQR of most of the other stressors (CV 77\%, IQR 0-2.49; Fig. 1).

\section{DisCUSSION}

All 50 of the Great Lakes stressors in our elicitation were judged to impact ecosystem condition, suggesting that management and restoration actions must address a multiplicity of threats rather than a few high-profile stressors or broad categories, as has been common practice (Table 1). The importance of accounting for impacts of many co-occurring stressors is in line with findings in other ecosystems (Halpern et al. 2007, Teck et al. 2010). However, we also found clear agreement among experts that these stressors differ greatly in their potential ecosystem impact. Average ratings varied by about two units on the $\log _{10}$ scales we defined for the components of impact, suggesting a roughly 100 -fold difference in potential impact between the highest- (e.g., zebra and quagga mussels) and lowest-rated (e.g., coastal recreational use) stressors. The general agreement among experts on the relative ecological importance of stressors indicates that our results are a robust starting point for restoration and management planning.

Most of the eight categories of stressors had wide variation in ratings among their constituent stressors, underscoring the need to "unpack" these coarse categories into individual stressors to capture the wide variation in impact among stressors within categories. The Great Lakes Restoration Initiative and other recent efforts have highlighted similar categories of stressors as those used in our study, particularly invasive species, toxic chemicals, land use changes, and nonpoint source pollution (Table 1; NYSDEC 2006, Lake Ontario Biodiversity Strategy Working Group 2009: Appendix C). Our study was one of the first to assess multiple stressors quantitatively across the entire Great Lakes. In

TABLE 5. Ranks of the five highest-rated environmental stressors by ecosystem zone based on expert elicitation in the Laurentian Great Lakes; rankings are also reported when a stressor was ranked 1-5 in an individual ecosystem zone.

\begin{tabular}{lccccccc}
\hline \hline \multicolumn{1}{c}{ Stressor } & $\begin{array}{c}\text { All zones } \\
(n=81)\end{array}$ & $\begin{array}{c}\text { Wetland/ ri. } \\
(n=58)\end{array}$ & $\begin{array}{c}\text { Lit. hard } \\
(n=38)\end{array}$ & $\begin{array}{c}\text { Lit. soft } \\
(n=46)\end{array}$ & $\begin{array}{c}\text { Sublit. hard } \\
(n=22)\end{array}$ & $\begin{array}{c}\text { Sublit. soft } \\
(n=34)\end{array}$ & $\begin{array}{c}\text { Off shore } \\
(n=24)\end{array}$ \\
\hline Invasive mussels & 1 & 1 & 1 & 1 & 1 & 1 & 1 \\
Climate change, temperature & 2 & 3 & 4 & 3 & 5 & 4 & 2 \\
Invasive ballast risk & 3 & 2 & 2 & 2 & 2 & 2 \\
Invasive lamprey & 4 & 15 & 6 & 7 & 6 & 6 & 3 \\
Climate change, water levels & 5 & 4 & 7 & 5 & 7 & 3 & 5 \\
Invasive fish & 7 & 6 & 3 & 4 & 3 & 5 \\
Diporeia decline & 9 & 36 & 5 & 6 & 4 & 15 & 29 \\
Invasive emergent plants & 17 & 5 & 12 & 11 & 23 & & 15 \\
\hline
\end{tabular}

Notes: Ranks were derived from experts rating five components of ecosystem impact for each stressor in an indirect elicitation framework (Parts III and IV of survey). Experts selected the ecosystem zone to which their answers applied, or selected "All zones" if their responses applied to all ecosystem zones ( $n$ indicates the number of survey respondents for each ecosystem zone). Hard and soft refer to substrate types: coastal wetlands and rivermouths (wetland/ri.), littoral (lit.), sublittoral (sublit.), and offshore. 
contrast, the Biodiversity Conservation Strategies (BCS) assessed stressors in Lake Michigan and Lake Erie (Pearsall et al. 2013) using an online survey to allow a group of experts to rate the areal extent of impact, intensity of impact, and recovery time needed for small groups of stressors (Pearsall et al. 2012b). Despite their narrower scope and geographic focus and their grouping of multiple stressors with separate effects, the ratings of almost all groups of stressors assessed by both surveys showed similar rank order; the only notable exception was that shoreline alterations and extensions received less emphasis in our study (Pearsall et al. 2013; D. Pearsall, unpublished data). For inland and coastal waters more generally, the Millennium Ecosystem Assessment rated habitat change and nonpoint source pollution categories as having slightly higher impact than invasive species in the last 50-100 years (MA 2005), contrasting with the primacy of invasive species in our results. Marine stressor studies placed more emphasis on types of fishing, coastal development, and hypoxia (Halpern et al. 2007). These differences in stressor rankings suggest that customizing stressor ratings through expert elicitation for specific ecosystem types and geographic regions is important to ensure appropriate guidance for management and restoration efforts.

Our survey respondents particularly emphasized the impacts of some invasive and nuisance species and climate change. Having a few classes of invasive species rated highly was not surprising in itself. For example, the high ratings for invasive mussels were consistent with ongoing documentation of their profound influence on lake food webs and nutrient dynamics (Hecky et al. 2004, Fahnenstiel et al. 2010). Nevertheless, having four of the five highest-rated stressors related to invasive species was more emphasis than we expected. High ratings for climate change effects were unexpected as well, since it had not been identified as a priority action topic until recently (e.g., White House Council on Environmental Quality 2010). Other stressors of longstanding importance, such as biomagnifying toxic chemicals and phosphorus pollution, were relegated to lower ranking positions, potentially indicating a shift in focus among experts compared to past decades. Interestingly, while comparison of ratings for the stressors using direct elicitation vs. indirect elicitation revealed broad similarities, some of the stressors that ranked higher in direct elicitation accorded with these longstanding stressors or with our impressions of current public attention. For example, phosphorus loading and coastal development have been highlighted in the past (Table 1), while harmful algal blooms are receiving extra attention due to blooms in western Lake Erie affecting recreation and drinking water in recent years (e.g., Michalak et al. 2013). These apparent shifts in stressor emphasis underscore the value of formal expert elicitations in documenting current thinking and providing a baseline for future studies of how perceptions and priorities shift through time.

Surprisingly, differences in stressor impact across habitats (lakes and ecosystem zones) of the Great Lakes were small (much less pronounced than differences among stressors), in contrast to findings from the similar elicitation for the California Current, where habitat differences were large (Teck et al. 2010). One possible explanation for this contrast is that individual habitat types and the biological communities within them are more distinct in marine systems (e.g., kelp forest vs. coral reef) than in the Great Lakes (e.g., coastal wetland vs. littoral zone vegetation), where many biotic and abiotic structuring factors exhibit gradual, continuous variation (McKenna and Castiglione 2010, Larson et al. 2013). Supporting this, the BCS survey of threats by location (ecosystem zone and basin) within Lake Michigan had similar findings to our survey: their summarized scores for offshore, nearshore, and coastal wetland zones within an area of the lake rarely varied by more than one point on their four-point scale (Pearsall et al. 2012b). Thus, a genuine contrast in the distinctiveness of habitats between marine systems and the Great Lakes is likely, though it is also possible that Great Lakes experts are simply less inclined to customize their responses for habitats. Indeed, Great Lakes experts identified habitat-specific effects for some stressors that match field-based studies. For example, the high ratings of invasive emergent plants in wetlands and rivermouths align with current observations of Phragmites australis subsp. australis (common reed) invasion decreasing plant taxa richness in coastal wetlands (Trebitz and Taylor 2007). Similarly, the high ratings for the decline of the amphipod Diporeia in deeper parts of the lakes matched field-based observations that they are essential prey for fish populations in offshore waters (Auer et al. 2013). Thus, while habitat differences still must be considered in stressor management decisions, our results suggest that conservation planning at broader scales than individual lakes or ecosystem zones may be a viable strategy, as exemplified by the approach taken under the Great Lakes Restoration Initiative.

We found surprisingly high levels of agreement among Great Lakes experts, as revealed by the low variance in their stressor ratings. This contrasted with previous marine work (Halpern et al. 2007), suggesting that our findings were not solely driven by respondents having similar training or work activities. Several other explanations are possible. First, efforts within the Great Lakes community to develop plans and policy stances over the last few decades have fueled communication and collaboration among scientists and practitioners across the basin, and the policy documents coming out of these efforts (such as the Great Lakes Water Quality Agreement, ratified in 1972 and renegotiated periodically since) are widely accepted as frameworks guiding research and remediation (Krantzberg 2012). Second, decades of media emphasis on particular stressors could 
result in apparent consensus due to shared biases in awareness. Beyond these historical mechanisms, a third possibility is one often claimed from stakeholder modeling exercises (Hobbs et al. 2002, Bousquet and Voinov 2010, Metcalf et al. 2010): indirect elicitation methods like those used in our survey allow all respondents to conceptualize the issue at hand in the same way despite their underlying differences in perspective. For example, the five components of ecosystem impact (Table 2) established a common framework for respondents to consider different pathways of impact. Supporting this, we found differences by respondent group in the direct, category-wide weights, but less variation among respondents within the indirect framework. Further studies would be needed to assess the role of each of these mechanisms in creating a high degree of agreement among Great Lakes experts despite their diverse employment sectors, geographic domains, and stressor expertise.

In addition to prioritizing among stressors for remediation efforts at broad spatial scales, quantitative ratings from expert elicitations can be paired with spatial data for specific applications (Halpern et al. 2009, Malczewski 2010). In the Great Lakes, many stressors show geographic overlap in their occurrence, with 9-28 stressors having above-average intensities in locations with high cumulative stress (Allan et al. 2013). Given that planning processes in the region are moving towards finer-scale spatial recommendations (e.g., White House Council on Environmental Quality 2010, Pearsall et al. 2013), future integration of elicitation data with maps of stressors, ecosystem services, and biodiversity significance are likely to enable a breadth of new applications in conservation planning.

Ideally, one would account for synergistic and antagonistic effects of co-occuring stressors in impact ratings to address nonlinearities and thresholds in ecosystems over space and time (Groffman et al. 2006). Stressor interactions are broadly reported in terrestrial (e.g., Aber et al. 2001), stream (Townsend et al. 2008), estuarine (Breitburg et al. 1999), and marine environments (Crain et al. 2008), and such interactions surely occur in the Great Lakes as well. For example, recent bird deaths from botulism outbreaks are hypothesized to result from links among several interacting stressors: increased water clarity from invasive dreissenid mussels may drive Cladophora (nuisance benthic algae) blooms, which create hypoxic conditions on the bottom where toxin-producing bacteria (Clostridium botulinum) multiply; birds may subsequently be poisoned by eating toxin-laden invasive round gobies (Neogobius melanostomus) as well as invasive mussels and other invertebrates (Chun et al. 2013). Past expert elicitations have uncovered challenges in assessing such effects across dozens of stressors (e.g., Hobbs et al. 2002), but quantitative assessments may be possible with a smaller set of stressors identified as most likely to have interactive effects. It is possible that our respondents sometimes took these effects into account, but we did not use follow-up interviews or additional open-ended questions to explore such complex patterns in cognitive reasoning.

In conclusion, prioritization of multiple stressors is increasingly important as ecosystem-based management and large-scale restoration projects (e.g., Chesapeake Bay, Puget Sound, Everglades [Van Cleve et al. 2004]) tackle dozens of environmental stressors, particularly in landscapes where stakeholders have competing desires. Budget limitations necessitate thoughtful choices, and the empirical determination of the relative impacts of all major stressors in a location is rarely an option, especially at large spatial scales where all possible combinations of stressors may occur. Expert elicitation offers an effective tool to gather information about relative impacts of diverse stressors, as demonstrated in this study. Restoration investments could pay off greatly for the millions of people in the region that rely on the resources, supporting services, recreation, and livelihoods provided by these inland oceans (e.g., MA 2005, Austin et al. 2007, Vaccaro and Read 2011, Allan et al. 2013). As regional, national, and international concern about the degradation of the Great Lakes grows, our stressor impact ratings offer a new perspective with diverse applications in identifying strategic restoration opportunities.

\section{ACKNOWLEDGMENTS}

We heartily thank the hundreds of Great Lakes scientific and management experts who generously shared their time to complete the survey. M. Carlson Mazur, B. Bunnell, and M. Khoury tested and provided feedback on an early draft of the survey, and R. Hecky and especially G. Kolenic provided additional input on the survey. W. L. Chadderton, T. Eder, and S. P. Sowa provided helpful input during the project. D. Schimel and anonymous reviewers provided constructive feedback on earlier versions of the manuscript. Funding was provided by the Fred A. and Barbara M. Erb Family Foundation. Continuing support was provided by the University of Michigan Water Center to D. Allan and S. Smith, and by the National Science Foundation (DEB-1115025) and Upper Midwest and Great Lakes Landscape Conservation Cooperative to P. McIntyre. D. Pearsall graciously shared survey data collected by The Nature Conservancy. This is NOAA GLERL contribution \#1729.

\section{Literature Cited}

Aber, J., R. P. Neilson, S. McNulty, J. M. Lenihan, D. Bachelet, and R. J. Drapek. 2001. Forest processes and global environmental change: predicting the effects of individual and multiple stressors. BioScience 51:735-751.

Allan, J. D. et al. 2013. Joint analysis of stressors and ecosystem services to enhance restoration effectiveness. Proceedings of the National Academy of Sciences USA 110:372-377.

Aspinall, W. 2010. A route to more tractable expert advice. Nature 463:294-295.

Auer, M. T., N. A. Auer, N. R. Urban, and T. Auer. 2013. Distribution of the amphipod Diporeia in Lake Superior: The ring of fire. Journal of Great Lakes Research 39:33-46.

Austin, J. C., S. Anderson, P. N. Courant, and R. E. Litan. 2007. Healthy waters, strong economy: the benefits of restoring the Great Lakes ecosystem. Metropolitan Policy Program, Brookings Institution, Washington, D.C. USA. 
Bails, J., A. Beeton, J. Bulkley, M. DePhilip, J. Gannon, M. Murray, H. Regier, and D. Scavia. 2005. Prescription for Great Lakes ecosystem protection and restoration: avoiding the tipping point of irreversible changes. http://healthylakes. org/wp-content/uploads/2011/01/Prescription-for-Great-LakesRestorationFINAL.pdf

Bikhchandani, S., D. Hirshleifer, and I. Welch. 1992. A theory of fads, fashion, custom, and cultural change as informational cascades. Journal of Political Economy 100:992-1026.

Bousquet, F., and A. Voinov. 2010. Preface to this thematic issue. Environmental Modelling and Software 25:1267.

Brazner, J. C. et al. 2007. Evaluation of geographic, geomorphic and human influences on Great Lakes wetland indicators: a multi-assemblage approach. Ecological Indicators 7:610-635.

Breitburg, D. L., J. G. Sanders, C. C. Gilmour, C. A. Hatfield, R. W. Osman, G. F. Riedel, S. P. Seitzinger, and K. G. Sellner. 1999. Variability in responses to nutrients and trace elements, and transmission of stressor effects through an estuarine food web. Limnology and Oceanography 44:837863.

Burgman, M., A. Carr, L. Godden, R. Gregory, M. McBride, L. Flander, and L. Maguire. 2011. Redefining expertise and improving ecological judgment. Conservation Letters 4:8187.

Chun, C. L., U. Ochsner, M. N. Byappanahalli, R. L. Whitman, W. H. Tepp, G. Lin, E. A. Johnson, J. Peller, and M. J. Sadowsky. 2013. Association of toxin-producing Clostridium botulinum with the macroalga Cladophora in the Great Lakes. Environmental Science and Technology 47:2587-2594.

Crain, C. M., K. Kroeker, and B. S. Halpern. 2008. Interactive and cumulative effects of multiple human stressors in marine systems. Ecology Letters 11:1304-1315.

Environment Canada and U.S. Environmental Protection Agency (USEPA). 2009. State of the Great Lakes 2009. binational.net/solec/sogl2009_e.html

Fahnenstiel, G. L., T. Nalepa, S. Pothoven, H. Carrick, and D. Scavia. 2010. Lake Michigan lower food web: long-term observations and Dreissena impact. Journal of Great Lakes Research 36(S3):1-4.

Franks Taylor, R. et al. 2010. The Sweetwater Sea: an international biodiversity conservation strategy for Lake Huron - technical report. http://www.conservationgateway. org/ConservationByGeography/NorthAmerica/UnitedStates/ michigan/Pages/lakehuron.aspx

Great Lakes Regional Collaboration (GLRC). 2005. Great Lakes regional collaboration strategy: to restore and protect the Great Lakes. http://www.glrc.us/strategy.html

Groffman, P. M., et al. 2006. Ecological thresholds: the key to successful environmental management or an important concept with no practical application? Ecosystems 9:1-13.

Halpern, B. S., and R. Fujita. 2013. Assumptions, challenges, and future directions in cumulative impact analysis. Ecosphere 4:art131.

Halpern, B. S., C. V. Kappel, K. A. Selkoe, F. Micheli, C. M. Ebert, C. Kontgis, C. M. Crain, R. G. Martone, C. Shearer, and S. J. Teck. 2009. Mapping cumulative human impacts to California Current marine ecosystems. Conservation Letters 2:138-148.

Halpern, B. S., K. A. Selkoe, F. Micheli, and C. V. Kappel. 2007. Evaluation and ranking the vulnerability of global marine ecosystems to anthropogenic threats. Conservation Biology 21:1301-1315.

Hecky, R. E., R. E. H. Smith, D. R. Barton, S. J. Guildford, W. D. Taylor, M. N. Charleton, and T. Howell. 2004. The nearshore phosphorus shunt: a consequence of ecosystem engineering by dreissenids in the Laurentian Great Lakes. Canadian Journal of Fisheries and Aquatic Sciences 61:12851293.

Hobbs, B. F., S. A. Ludsin, R. L. Knight, P. A. Ryan, J. Biberhofer, and J. J. H. Ciborowski. 2002. Fuzzy cognitive mapping as a tool to define management objectives for complex ecosystems. Ecological Applications 12:1548-1565.

International Joint Commission (IJC). 2011. 15th biennial report on Great Lakes water quality. http://www.ijc.org/en_/ Reports_and_Publications

Kappel, C. V., B. S. Halpern, K. A. Selkoe, and R. M. Cooke. 2012. Eliciting expert knowledge of ecosystem vulnerability to human stressors to support comprehensive ocean management. Pages 253-277 in A. H. Perera, C. A. Drew, and C. J. Johnson, editors. Expert knowledge and its application in landscape ecology. Springer Science + Business Media, New York, New York, USA.

Keough, J. R., T. A. Thompson, G. R. Guntenspergen, and D. A. Wilcox. 1999. Hydrogeomorphic factors and ecosystem responses in coastal wetlands of the Great Lakes. Wetlands 19:821-834.

Krantzberg, G. 2012. Renegotiation of the 1987 Great Lakes Water Quality Agreement: from confusion to promise. Sustainability 4:1239-1255.

Lake Ontario Biodiversity Strategy Working Group. 2009. The beautiful lake: a bi-national biodiversity conservation strategy for Lake Ontario. http://www.conservationgateway.org/ ConservationByGeography/NorthAmerica/UnitedStates/ michigan/Pages/lakeontario.aspx

Larson, J. H., A. S. Trebitz, A. D. Steinman, M. J. Wiley, M. Carlson Mazur V. Pebbles, H. A. Braun, and P. W. Seelbach. 2013. Great Lakes rivermouth ecosystems: scientific synthesis and management implications. Journal of Great Lakes Research 59:513-524.

Low Choy, S., R. O'Leary, and K. Mengersen. 2009. Elicitation by design in ecology: using expert opinion to inform priors for Bayesian statistical models. Ecology 90:265-277.

Malczewski, J. 2010. Multiple criteria decision analysis and geographic information systems. Pages 369-396 in M. Ehrgott, J. R. Figueira, and S. Greco, editors. Trends in multiple criteria decision analysis. Springer, New York, New York, USA.

Martin, T. G., M. A. Burgman, F. Fidler, P. M. Kuhnert, S. Low-Choy, M. Mcbride, and K. Mengersen. 2012. Eliciting expert knowledge in conservation science. Conservation Biology 26:29-38.

McKenna, J. E., and C. Castiglione. 2010. Hierarchical multiscale classification of nearshore aquatic habitats of the Great Lakes: western Lake Erie. Journal of Great Lakes Research 36:757-771.

Metcalf, S. S., E. Wheeler, T. K. BenDor, K. S. Lubinski, and B. M. Hannon. 2010. Sharing the floodplain: mediated modeling for environmental management. Environmental Modelling and Software 25:1282-1290.

Michalak, A. M., et al. 2013. Record-setting algal bloom in Lake Erie caused by agricultural and meteorological trends consistent with expected future conditions. Proceedings of the National Academy of Sciences USA 110:6448-6452.

Millennium Ecosystem Assessment (MA). 2005. Ecosystems and human well-being: wetlands and water-synthesis. World Resources Institute, Washington, D.C. USA

New York State Department of Environmental Conservation (NYSDEC). 2006. Comprehensive wildlife conservation strategy plan. http://www.dec.ny.gov/animals/30483.html

Pearsall, D., et al. 2012a. Returning to a healthy lake: Lake Erie biodiversity conservation strategy - technical report. http:// www.conservationgateway.org/ConservationByGeography/ NorthAmerica/UnitedStates/michigan/Pages/lakeerie.aspx

Pearsall, D., et al. 2012b. Michigami: great water. Strategies to conserve the biodiversity of Lake Michigan-technical report. http://www.conservationgateway.org/ConservationBy Geography/NorthAmerica/UnitedStates/michigan/Pages/ lakemichigan.aspx

Pearsall, D. R., M. L. Khoury, J. Paskus, D. Kraus, P. J. Doran, S. P. Sowa, R. Franks Taylor, and L. K. Elbing. 2013. "Make no little plans": developing biodiversity 
conservation strategies for the Great Lakes. Environmental Reviews and Case Studies 15:462-480.

R Development Core Team. 2011. R: a language and environment for statistical computing. $\mathrm{R}$ Foundation for Statistical Computing, Vienna, Austria. http://www. r-project.org/

Riseng, C. M., M. J. Wiley, R. W. Black, and M. D. Munn. 2011. Impacts of agricultural land use on biological integrity: a causal analysis. Ecological Applications 21:3128-3146.

Rodríguez Iglesias, R. M., and M. M. Kothmann. 1998. Evaluating expert knowledge: plant species responses to cattle grazing and fire. Journal of Range Management 51:332-344.

Salafsky, N., et al. 2008. A standard lexicon for biodiversity conservation: unified classifications of threats and actions. Conservation Biology 22:897-911.

Steinman, A. D., K. E. Havens, and L. Hornung. 2002. The managed recession of Lake Okeechobee, Florida: integrating science and natural resource management. Conservation Ecology 6:17.

Teck, S. J., et al. 2010. Using expert judgment to estimate marine ecosystem vulnerability in the California Current. Ecological Applications 20:1402-1416.

Townsend, C. R., S. S. Uhlmann, and C. D. Matthaei. 2008. Individual and combined responses of stream ecosystems to multiple stressors. Journal of Applied Ecology 45:1810-1819.

Trebitz, A. S., J. C. Brazner, N. P. Danz, M. S. Pearson, G. S. Peterson, D. K. Tanner, D. L. Taylor, C. W. West, and T. P. Hollenhorst. 2009. Geographic, anthropogenic, and habitat influences on Great Lakes coastal wetland fish assemblages. Canadian Journal of Fisheries and Aquatic Sciences 66:13281342.
Trebitz, A. S., and D. L. Taylor. 2007. Exotic and invasive aquatic plants in Great Lakes coastal wetlands: distribution and relation to watershed land use and plant richness and cover. Journal of Great Lakes Research 33:705-721.

Vaccaro, L., and J. Read. 2011. Vital to our nation's economy: Great Lakes jobs report. MICHU-11-203. Michigan Sea Grant. http://www.miseagrant.umich.edu/explore/coastalcommunities/economic-vitality-and-the-great-lakes/

Van Cleve, F. B., C. Simenstad, F. Goetz, and T. Mumford. 2004. Application of "best available science" in ecosystem restoration: lessons learned from large-scale restoration efforts in the USA. Puget Sound nearshore partnership report No. 2004-01. Washington Sea Grant Program, University of Washington, Seattle, Washington, USA.

Weber, M., and K. Borcherding. 1993. Behavioral influences on weight judgments in multiattribute decision making. European Journal of Operational Research 67:1-12.

Welch, B. L. 1951. On the comparison of several mean values: an alternative approach. Biometrika 38: 330-336.

White, P. C. L., N. Vaughan Jennings, A. R. Renwick, and N. H. L. Barker. 2005. Questionnaires in ecology: a review of past use and recommendations for best practice. Journal of Applied Ecology 42:421-430.

White House Council on Environmental Quality, et al. 2010. Great Lakes restoration initiative action plan. http://www. glri.us/priorities.html

Wohl, E., P. L. Angermeier, B. Bledsoe, G. M. Kondolf, L. MacDonnell, D. M. Merritt, M. A. Palmer, N. L. Poff, and D. Tarboton. 2005. River restoration. Water Resources Research 41:W10301.

Zar, J. H. 1999. Biostatistical analysis. Fourth edition. Prentice Hall, Upper Saddle River, New Jersey, USA.

\section{Supplemental Material}

\section{Ecological Archives}

Appendices A and B and the Supplement are available online: http://dx.doi.org/10.1890/14-0366.1.sm 